RESEARCH NOTE

\section{Do late bilinguals access pure morphology during word recognition? A masked-priming study on Hebrew as a second language*}

\author{
YAEL FARHY \\ Potsdam Research Institute for Multilingualism \\ J O ÃO VERÍ S S IMO \\ Potsdam Research Institute for Multilingualism \\ HARALD CLAHSEN \\ Potsdam Research Institute for Multilingualism
}

(Received: August 11, 2017; final revision received: December 17, 2017; accepted: January 06, 2018; first published online 13 June 2018)

This study extends research on morphological processing in late bilinguals to a rarely examined language type, Semitic, by reporting results from a masked-priming experiment with 58 non-native, advanced, second-language (L2) speakers of Hebrew in comparison with native (L1) speakers. We took advantage of a case of 'pure morphology' in Hebrew, the so-called binyanim, which represent (essentially arbitrary) morphological classes for verbs. Our results revealed a non-native priming pattern for the L2 group, with root-priming effects restricted to non-finite prime words irrespective of binyanim type. We conclude that root extraction in L2 Hebrew word recognition is less sensitive to both morphological and morphosyntactic cues than in the L1, in line with the Shallow-Structure Hypothesis of L2 processing.

Keywords: grammatical processing, morphology, behavioural measurements, healthy normal subjects, Hebrew

\section{Introduction}

Do non-native, late bilinguals make use of morphological and morphosyntactic information during online word recognition in the same way as native speakers? Although this question has received a lot of attention in recent experimental research, the matter is still controversial. Some researchers have claimed that native (L1) and nonnative (L2) speakers apply the same mechanisms for processing morphologically complex words, but that L2 processing may be negatively affected by difficulties with lexical access or retrieval, working memory limitations, and/or slower processing speed (e.g., Cunnings, 2017; Hopp, 2016; McDonald, 2006). Alternatively, more substantial L1/L2 differences have been posited by the Shallow-Structure Hypothesis ( $\mathrm{SSH}$ ), originally for sentence processing (Clahsen \& Felser, 2006a, 2006b) and later extended to morphological processing (e.g., Clahsen, Felser, Neubauer, Sato \& Silva, 2010; Clahsen, Balkhair, Schutter \& Cunnings, 2013; Clahsen, Gerth, Heyer \& Schott, 2015). The SSH holds that even

\footnotetext{
* This work was supported by a Ph.D. scholarship awarded to YF by the Minerva Fellowship Program and an Alexander-von-Humboldt Professorship awarded to HC. We are grateful to Natalie Uziel and Ella Avner for their help with testing and recruiting participants. We also thank two anonymous reviewers for helpful comments on a previous version of this manuscript.
}

proficient L2 speakers tend to have problems building or manipulating abstract grammatical representations in real time, and that relative to native speakers, L2 processing of morphologically complex words relies more heavily on storage of complex forms and less on morphological structure and computation. In experimental research, priming experiments (specifically, masked priming) have been widely used as a technique to provide insight into the kinds of cues the word recognition system relies on during morphological processing (see Marslen-Wilson, 2007, for a review). Previous L2 priming studies, however, have produced mixed results. For inflection, for example, some studies reported L1-like morphological priming effects for English past-tense forms and for French -er verbs in groups of late bilinguals, even under maskedpriming conditions (e.g., Coughlin \& Tremblay, 2015; Feldman, Kostić, Basnight-Brown, Đurđević \& Pastizzo, 2010; Voga, Anastassiadis-Symeonidis \& Giraudo, 2014), whereas other studies found morphological facilitation effects for inflectional phenomena in English, German, and Turkish for their L1 control groups, but not for groups of (highly proficient) late bilinguals (e.g., Jacob, Heyer \& Veríssimo, 2017; Kirkici \& Clahsen, 2013; Neubauer \& Clahsen, 2009; Silva \& Clahsen, 2008). The question of whether an inflected word's morphological structure and its morphosyntactic features (e.g., finiteness features) are underused in L2 processing or whether the L2 system employs these information 
sources in the same way as the L1 system remains to be answered.

Against this background, this study reports the results from a masked-priming experiment on late bilinguals' processing of Hebrew inflectional morphology, the first L2 study of its kind on a previously unconsidered language type (Semitic). Due to its non-concatenative properties, the Semitic lexical processor has been claimed to be primarily driven by morphology, designed to extract a complex word's abstract structure (root and word pattern), irrespective of meaning or surface form (Boudelaa \& Marslen-Wilson, 2015; Frost, Forster \& Deutsch, 1997). With those properties, Hebrew morphology should be an ideal test case to test the role of morphology during L2 word recognition.

\section{Background: Hebrew morphology}

There is an extensive linguistic and psycholinguistic literature on this topic (see, e.g., Arad, 2005; Aronoff, 1994; Frost et al., 1997; Plaut \& Gonnermann, 2000), which will not be discussed here. Rather, the following remarks are meant as background information for those unfamiliar with Hebrew morphology and the corresponding experimental research.

Hebrew composes most words non-concatenatively, by a non-linear combination of a consonantal root and a vowel pattern, which together constitutes stems to which inflectional affixes may be added. The consonantal root typically contains three consonants and carries the core meaning of the word. The same root is commonly assigned to more than one pattern. For verbs there are seven distinct vowel patterns called binyanim, which provide designated positions for inserting a root's consonants. For example, the verb katav '(he) wrote' consists of the root K-T-V and the binyan Paal, which is expressed by the vowel pattern $\mathrm{CaCaC}$ (with ' $\mathrm{C}$ ' representing the root consonants). While two binyanim (Pual and Hufal) are fully predictable in their morphosyntactic function (encoding passive voice), the other five classes show only general semantic and syntactic tendencies (for review, see Arad, 2005). In fact, for many Hebrew verbs, it is generally difficult or impossible to compute their meaning compositionally on the basis of roots and patterns. Furthermore, binyanim assignment is obligatory, with every verb having to be assigned to a binyan before it can be inflected. Aronoff (1994, chapter 5) points out that with these properties the Hebrew binyanim may be conceived as a system of inflectional classes, akin to the conjugational classes in the Romance languages. As such, the binyanim are not morphemic - in the sense of reliably encoding particular syntactic or semantic properties - but instead serve as an abstract morphological mark of a given verb's inflectional class, which dictates the phonological shape of its different forms (Aronoff, 1994, p. 127).
Table 1. Properties of the Paal and Piel classes

\begin{tabular}{llll}
\hline \hline Class & $\begin{array}{l}\text { Phonological } \\
\text { base form }\end{array}$ & Example & $\begin{array}{l}\text { Type } \\
\text { frequency }\end{array}$ \\
\hline Paal & $\mathrm{CaCaC}$ & lamad 'learned' & $19.4 \%$ \\
Piel & $\mathrm{CiCeC}$ & limed 'taught' & $17.1 \%$ \\
\hline \hline
\end{tabular}

For the present study, we examined the two most common binyanim, Paal and Piel. While both classes have relatively high type frequencies (calculated as percentages of verbs of each class in a corpus containing 4,131 verbs; Itai \& Wintner, 2008), they differ in their productivity (see Table 1). New verbs are typically assigned to Piel, whereas Paal forms represent a restricted class of lexical items in Modern Hebrew (see Bolozky, 1999).

Hebrew (and Arabic) morphology has been subject to a large number of experimental studies, albeit almost exclusively with native speakers (Boudelaa \& MarslenWilson, 2005; Deutsch, Frost \& Forster, 1998; Frost et al., 1997; Frost, Kugler, Deutsch \& Forster, 2005). One familiar finding from this research is a ROOTPRIMING EFFECT, that is, faster lexical decision times for a target word (e.g., mixtav 'a letter') when the prime shares the same consonantal root, relative to an unrelated control prime (e.g., hixtiv '(he) dictated' $\rightarrow$ mixtav vs. hirgish '(he) felt' $\rightarrow$ mixtav). Interestingly, a rootpriming effect was obtained even when prime and target were not transparently related in meaning (e.g., rasham '(he) registered' $\rightarrow$ hirshim '(he) impressed'). How to interpret root-priming effects is controversial. Root priming may signal full morphological decomposition of every complex Hebrew or Arabic word form into root and pattern (e.g., Boudelaa \& Marslen-Wilson, 2011, 2015). Alternatively, root-priming effects have been interpreted in terms of additive or interactive effects of prime-target overlap in form and meaning, even under masked-priming conditions (e.g., Plaut \& Gonnerman, 2000; see also Gonnerman, Seidenberg \& Andersen, 2007).

Further insight into the nature of morphological priming in Hebrew comes from a recent masked-priming study that showed reliable root-priming effects from Piel primes, but not from Paal primes, with a group of L1 Hebrew speakers (Farhy, Veríssimo \& Clahsen, 2017). The authors attributed this contrast to distinct morpholexical representations for the two binyanim, structured fully decomposable stems for productive classes (like Piel) versus unstructured stems that are stored as wholes for unproductive classes (like Paal).

Little is known about late bilinguals' processing of Semitic morphology. Two recent studies provide insight into how L2 speakers handle its non-concatenative morphology. Norman, Degani and Peleg (2016) found that in L1 and L2 Hebrew speakers (the latter with either 
Table 2. Experimental conditions, with an example stimulus set

\begin{tabular}{|c|c|c|c|c|}
\hline \multirow[b]{2}{*}{ Form type } & \multirow[b]{2}{*}{ Target (Hitpael) } & \multicolumn{3}{|c|}{ Prime type } \\
\hline & & Unrelated & Paal & Piel \\
\hline \multirow{4}{*}{ 1sg Past } & התאבד & משכתי & אבדתי - אבי & איבדתי \\
\hline & ht?bd & mSkty & Pbdty & Pybdty \\
\hline & /hit?abed/ & /mafaxti/ & /avadti/ & /ibadti/ \\
\hline & 'committed suicide' & 'pulled' & 'was lost' & 'lost' \\
\hline \multirow{4}{*}{ Infinitive } & התחלק & לשפר & 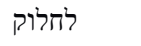 & 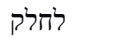 \\
\hline & htxlq & $1 \mathrm{Spr}$ & lxlwq & lxlq \\
\hline & /hitxalek/ & /lefaper/ & /laxlok/ & /lexalek/ \\
\hline & '(was) shared/divided' & 'to improve' & 'to share' & 'to divide' \\
\hline
\end{tabular}

Note: Examples are shown in Hebrew orthography together with transliteration to Latin letters, phonological form, and English translation.

Arabic or English as L1), pseudowords composed from existing roots and vowel patterns yielded longer lexicaldecision times than pseudowords composed from nonexisting roots or vowel patterns. The authors interpreted this finding as signalling native-like decomposition of Hebrew words into roots and patterns in L2 Hebrew. Alternatively, however, it is possible that pseudowords with existing roots and vowel patterns take longer to reject (relative to pseudowords constructed from non-existing component parts), because they are phonologically more similar to real words. In addition, in a cross-modal study (Freynik, Gor \& O'Rourke, 2017), root-priming effects of similar magnitudes were obtained in both L2 and L1 speakers of Arabic, which the authors interpret as signalling the use of native-like morphological decomposition into roots and patterns in L2 Arabic speakers. Alternatively, however, one may conceive of this finding as the result of the combined effects of overlap of form and meaning, given that cross-modal priming may be particularly sensitive to semantic effects (e.g., Gonnerman et al., 2007; Marslen-Wilson, Tyler, Waksler \& Older, 1994).

In the present study, we examine whether late bilinguals access pure morphology during word recognition in the same way as native speakers, by testing late bilinguals' sensitivity to the Hebrew binyanim - a case of pure morphology that is less directly derivable from formmeaning associations than the commonly studied grammatical morphemes. Specifically, we tested whether nonnative speakers showed root priming from verbs belonging to the productive Piel class and from the unproductive Paal class, presented in two different verbal forms (1 sg Past and Infinitive). In addition, we directly compared our results to a group of native speakers who underwent the same experiment (Farhy et al., 2017) and showed robust priming from Piel, but not from Paal forms. If non-native speakers are sensitive to the distinction between verbal classes, they should show the same priming pattern as the L1 control group. However, if L2 speakers underuse morphological information, they should show similar effects following Paal and Piel primes.

\section{Method}

\section{Participants}

Fifty-eight non-native Hebrew speakers ( 35 males, 7 lefthanded, mean age: 28.69 , SD: 4.46) participated in the experiment. They all lived in Israel and had emigrated from South America, with Spanish $(\mathrm{n}=55)$ or Portuguese $(n=3)$ as their native language. All participants were late learners of Hebrew (mean age of onset: 14.0 years, SD: 4.61) and achieved a mean score of $96 \%(\mathrm{SD}=$ 0.08 ) in one section of the YAEL proficiency test for university candidates (including sentence completion, sentence rephrasing, and reading comprehension), with every participant achieving a $70 \%$ score or higher. Participants also estimated (in percentages) their relative use of Hebrew, both overall, and in four specific domains (speaking, hearing, writing, and reading). Hebrew had a mean overall usage of $60.96 \%(\mathrm{SD}=18.94)$. Similar usage ratings were reported for the four specific domains (speaking: 61.56\%; hearing: 61.84\%; writing: 67.39\%; reading: $63.18 \%$ ). Participants used their native languages (Spanish or Portuguese) less often, with a mean overall usage of $28.95 \%$ (SD: 16.73). All participants had normal or corrected-to-normal vision and none had been diagnosed with any language disorders.

\section{Materials}

Table 2 displays the experimental design, including an example stimulus set. Experimental targets consisted of 42 Hitpael verbs, presented in the 3sg past tense, a form 
Table 3. Mean RTs and SEs (in parenthesis) and accuracy rates

\begin{tabular}{|c|c|c|c|c|c|c|c|}
\hline \multirow[b]{2}{*}{ Group } & \multirow[b]{2}{*}{ Form type } & \multicolumn{2}{|c|}{ Unrelated } & \multicolumn{2}{|l|}{ Paal } & \multicolumn{2}{|l|}{ Piel } \\
\hline & & RT (ms) & Acc. & RT (ms) & Acc. & RT (ms) & Acc. \\
\hline \multirow[t]{2}{*}{ L1 } & $1 \mathrm{sg}$ Past & $634(10.94)$ & $94 \%$ & $629(10.34)$ & $97 \%$ & $609(9.46)$ & $97 \%$ \\
\hline & Infinitive & $641(10.08)$ & $94 \%$ & $639(10.91)$ & $94 \%$ & $620(10.81)$ & $97 \%$ \\
\hline \multirow[t]{2}{*}{ L2 } & 1sg Past & 807 (13.74) & $85 \%$ & $820(15.68)$ & $86 \%$ & $818(14.72)$ & $88 \%$ \\
\hline & Infinitive & $819(13.77)$ & $80 \%$ & $790(14.90)$ & $79 \%$ & $794(13.55)$ & $82 \%$ \\
\hline
\end{tabular}

Note: The L1 data are from Farhy et al. (2017). Displayed means and SEs are back-transformed from a reciprocal transformation $(-1000 / \mathrm{RT})$, as this was the transformation used in the analysis of the L1 group reported in Farhy et al.

constituted by a root together with the Hitpael verbal pattern, with no inflectional suffixes. There were two sets of 21 targets, one for each of two Form Type conditions, 1 sg Past and Infinitive; as described below, Form Type refers to the particular form in which prime words were presented. Note that the experimental targets were always presented in their $3 \mathrm{sg}$ past-tense form. Each target word was paired with three types of primes: (a) one prime belonging to the Paal class, based on the same verbal root as the target, (b) one prime belonging to the Piel class, also based on the same root, and (c) one unrelated prime, which had no orthographic, phonological, or semantic overlap with its corresponding target form. The materials were the same as in Farhy et al. (2017).

Each target was preceded by Paal, Piel, and Unrelated primes presented either in a finite form, the 1sg past tense (21 targets), or in the infinitive form (21 targets) ${ }^{1}$. Conditions were matched for length, semantic relatedness, and lemma frequency (Itai \& Wintner, 2008). We also included 294 filler prime-target pairs, 126 wordword pairs and 168 word-nonword pairs, yielding a total of 336 targets, half of them words and half pseudowords (for additional descriptions, see Farhy et al., 2017).

\section{Procedure}

Participants were asked to perform a lexical decision task on visual targets, as quickly and accurately as possible. Every trial consisted of a fixation cross $(500 \mathrm{~ms})$, a blank screen $(500 \mathrm{~ms})$, a row of hash marks $(500 \mathrm{~ms})$, a prime word $(50 \mathrm{~ms})$, and the target (presented until a response was made, up to a timeout of $2000 \mathrm{~ms}$ ). After a further $500 \mathrm{~ms}$, the next trial started. Response times (RTs) were measured from the onset of target presentation.

1 The same targets could not be preceded by both forms because several primes could only appear as 1 sg past-tense forms due to Paal/Piel homography in the infinitive.

\section{Data analysis}

Two items with extremely low accuracy (below 50\%) were removed (hidama 'was similar' and hishtamer 'was preserved', both from the 1sg Past condition), in addition to incorrect responses and timeouts (i.e., when no response was made during the $2000 \mathrm{~ms}$ window). In addition, trials with extremely slow RTs (longer than $1,500 \mathrm{~ms}$ ) were removed $(6.84 \%)$. In order to compare the current priming effects to an L1 group, Farhy et al.'s (2017) data from 30 native Hebrew speakers (who underwent the same task and procedure) were added to the present dataset.

The RT data were analysed with generalised linear mixed-effects regression, with crossed random effects for participants and items (Baayen, Davidson \& Bates, 2008). RTs were analysed without any transformation, but with the assumption that the data follows an inverse Gaussian distribution (with an identity link function), as recommended by Lo and Andrews (2015). A detailed description of this kind of regression model is provided in Appendix S1 (Supplementary material), together with an assessment of the models' random structure. The following factorial predictors were included: (a) Prime Type (Paal, Piel, Unrelated), (b) Form Type (1sg Past, Infinitive), and (c) Group (L1, L2). In the presence of interactions, treatment contrasts were used and the statistical comparisons of interest were obtained by relevelling factors and refitting the model. In the cases where 'main effects' are reported, these were obtained by converting factors to numeric variables and centering them (e.g., Fraundorf \& Jaeger, 2016). Accuracy data were also analysed with generalised mixed-effects regression (binomial family, logit link function; Jaeger, 2008).

\section{Results}

Table 3 displays mean RTs, standard errors (SEs), and accuracy rates in all conditions, for the L2 speaker group in the present study, as well as for the L1 control group. 
In the accuracy data, a main effect of Group was obtained $(b=1.24, z=3.88, p<.001)$, indicating higher accuracy rates for the L1 group, across conditions, and an effect of Prime Type, indicating higher accuracy rates in the Piel prime condition, across groups (Unrelated vs. Piel: $b=0.45, z=2.74, p=.006$; Paal vs. Piel: $b=0.34$, $z=2.00, p=.045)$. Significant interactions between the predictors were not found (all $|z| \mathrm{s}<1.13$, all $p \mathrm{~s}>$.262).

With regard to the RTs, the analysis yielded significant three-way interactions between Prime Type, Form Type and Group, both for Paal priming $(b=-36.3, t=-2.47$, $p=.013)$ and Piel priming $(b=-34.7, t=-2.38, p=$ .017). These analyses were followed by separate withingroup analyses. For the L2 group, interactions between Prime Type and Form Type were significant, for both Paal priming $(b=-35.4, t=-2.34, p=.019)$ and Piel priming $(b=-37.1, t=-2.24, \mathrm{p}=.025)$, but not for the comparison between Paal and Piel $(b=1.7, t=0.11$, $p=.913$ ), indicating that the two binyanim show similar effects across the two forms. Further analyses revealed different priming patterns in the Infinitive and the $1 \mathrm{sg}$ Past conditions. In the Infinitive condition, Piel and Paal primes yielded significantly shorter RTs than Unrelated primes (Unrelated vs. Piel: $b=26.3, t=2.15, p=.032$; Unrelated vs. Paal: $b=22.0, t=2.01, p=.045)$. By contrast, primes presented in the $1 \mathrm{sg}$ Past condition did not produce any facilitation, neither for $\operatorname{Piel}(b=-10.78$, $t=-0.93, p=.350)$, nor for Paal primes $(b=-13.40, t$ $=-1.09, p=.275)^{2}$.

In the L1 group, similar priming effects were obtained in the Infinitive and the 1sg Past conditions, with no interactions between Prime Type and Form Type, neither for Paal $(b=2.1, t=0.13, \mathrm{p}=.895)$, nor for Piel priming $(b=-2.5, t=-0.15, p=.880)$. Across both Form Type conditions, Piel primes yielded significantly shorter RTs than Unrelated primes $(b=23.9, t=2.93$, $p=.003)$, whereas Paal primes did not produce any reliable facilitation $(b=2.07, t=0.25, p=.805)$, with a significant difference between RTs following Paal and Piel primes $(b=-21.8, t=-2.68, p=.007)$. In addition, an examination of each Form Type condition (despite the absence of interactions) showed significant priming from Piel in both the Infinitive and 1 sg Past (both $p$ s $<.049$ ), but no priming effects from Paal in neither of the two Form Types (both $p \mathrm{~s}>.786$ ).

\section{Discussion}

In the current masked-priming study, late L2 learners of Hebrew showed similar morphological root-priming effects for infinitive forms, regardless of whether verbs

2 Following a reviewer's concern that the higher L2 error rate could affect the results, we conducted a combined RT/accuracy analysis and found parallel results (see Appendix S2 in Supplementary material). belonged to the productive verbal class Piel or to the unproductive class Paal. However, when verbs were presented in a finite form (1sg past tense), no priming effects were obtained, neither for Paal nor for Piel verbs. Both of these findings stand in sharp contrast with the results obtained with the L1 group, for which root-priming effects were elicited by Piel verbs only, both when they were presented as infinitives and as finite forms. In other words, whereas for native speakers priming effects were modulated by binyan but not by finiteness, L 2 speakers showed the opposite pattern, with morphological priming being crucially dependent on finiteness but not on binyan membership.

The Hebrew binyanim have been argued to constitute a system of 'pure morphology', because they determine the phonological shape of verbal stems and are essentially arbitrary with regards to the syntactic or semantic properties that they express (Aronoff, 1994). The fact that L1 root-priming effects are modulated by binyan indicates that native speakers distinguish between these abstract morphological categories and use this information during visual word recognition, specifically, by decomposing stems of Piel verbs down to the level of the root or accessing whole stems in the case of the unproductive class Paal (see Farhy et al., 2017, for discussion). However, this account cannot be extended to the L2 data. The equivalent L2 effects for Paal and Piel - priming for infinitives, and no priming for finite forms - suggests instead that late-learners of Hebrew represent verbs from productive and unproductive classes in a similar way and, at least under masked-priming conditions, do not show sensitivity to purely morphological cues like binyan membership during the recognition of complex forms.

How can the L2 root-priming effects for infinitives be explained? One possibility is that L2 speakers of Hebrew recognise and extract root constituents from nonfinite forms (Freynik et al., 2017), for example, due to the root's salient role in Hebrew as a structural unit (Frost et al., 1997). Alternatively, the source of these facilitation effects may be that $\mathrm{L} 2$ speakers learn form-tomeaning lexical regularities, such as the co-occurrence of roots with certain semantic features (Plaut \& Gonnerman, 2000). Crucially, however, the process by which roots are pre-activated in L2 masked-priming is (a) equally applicable to verbs from all binyanim and (b) can be 'blocked' or made more difficult in the case of forms that contain a tense and agreement morpheme, as revealed by the lack of root priming from forms presented in the 1 sg past tense. Although not initially hypothesized, the contrast between facilitated decomposition of infinitives, but lack of priming from forms with finite morphemes, is reminiscent of production studies in which late learners show considerable difficulties with the overt expression of morphosyntactic features, instead producing infinitives and unmarked forms (e.g., Blom, Polišenská \& Weerman, 
2006; White, 2003). Prévost and White (2000), for example, suggested that (in production) access to finite forms is sometimes blocked, resulting in underspecified non-finite forms 'winning' the competition for lexical insertion, especially under pressure. Furthermore, the lack of priming from 1sg past-tense forms in our study is broadly consistent with a number of previous priming studies, in which late bilinguals show reduced facilitation from inflected forms and marked stems (e.g., Jacob et al., 2017; Veríssimo, Heyer, Jacob \& Clahsen, 2017; Krause, Bosch \& Clahsen, 2015; Silva \& Clahsen, 2008). The present findings therefore suggest that word recognition in advanced L2 learners is less sensitive to ВОТн morphological (binyan membership) and morphosyntactic cues (finiteness) than in native speakers.

Other proposed sources of L1 versus L2 contrasts, such as limited exposure and proficiency or nativelanguage influence cannot easily account for our results. Firstly, our L2 participants were all highly proficient and fully immersed speakers, who used Hebrew on a daily basis. Secondly, they were native speakers of Spanish or Portuguese, languages that also display verbal conjugation classes. Moreover, there is evidence that L1 speakers of Romance languages employ this purely morphological information during word recognition (Say \& Clahsen, 2002; Veríssimo \& Clahsen, 2009).

We conclude that even advanced late-learners are likely to show processing differences relative to L1 speakers, specifically in the domains of pure morphology and morphosyntax. More generally, our results are consistent with the Shallow-Structure Hypothesis (Clahsen \& Felser, 2006a, 2006b; Clahsen et al., 2010), according to which late bilinguals underuse grammatical information and analysis in the course of linguistic processing.

\section{Supplementary material}

To view supplementary material for this article, please visit https://doi.org/10.1017/S1366728918000032

\section{References}

Arad, M. (2005). Roots and patterns: Hebrew morpho-syntax. Dordrecht: Springer.

Aronoff, M. (1994). Morphology by itself: Stems and inflectional classes. Cambridge, MA: MIT Press.

Baayen, R. H., Davidson, D. J., \& Bates, D. M. (2008). Mixedeffects modeling with crossed random effects for subjects and items. Journal of Memory and Language, 59, 390-412.

Blom, E., Polišenská, D., \& Weerman, F. (2006). Effects of age on the acquisition of agreement inflection. Morphology, 16, 313-336.

Bolozky, S. (1999). Measuring productivity in word formation: The case of Israeli Hebrew. Leiden: Brill.
Boudelaa, S., \& Marslen-Wilson, W. D. (2005). Discontinuous morphology in time: Incremental masked priming in Arabic. Language and Cognitive Processes, 20, 207-260.

Boudelaa, S., \& Marslen-Wilson, W. D. (2011). Productivity and priming: Morphemic decomposition in Arabic. Language and Cognitive Processes, 26, 624-652.

Boudelaa, S., \& Marslen-Wilson, W. D. (2015). Structure, form, and meaning in the mental lexicon: Evidence from Arabic. Language, Cognition and Neuroscience, 30, 955-992.

Clahsen, H., Balkhair, L., Schutter, J. S., \& Cunnings, I. (2013). The time course of morphological processing in a second language. Second Language Research, 29, 7-31.

Clahsen, H., \& Felser, C. (2006a). Grammatical processing in language learners. Applied Psycholinguistics, 27, 3-42.

Clahsen, H., \& Felser, C. (2006b). How native-like is non-native language processing? Trends in Cognitive Sciences, 10, 564-570.

Clahsen, H., Felser, C., Neubauer, K., Sato, M., \& Silva, R. (2010). Morphological structure in native and nonnative language processing. Language Learning, 60, 21-43.

Clahsen, H., Gerth, S., Heyer, V., \& Schott, E. (2015). Morphology constrains native and non-native word formation in different ways: Evidence from plurals inside compounds. The Mental Lexicon, 10, 53-87.

Coughlin, C. E., \& Tremblay, A. (2015). Morphological decomposition in native and non-native French speakers. Bilingualism: Language and Cognition, 18, 524-542.

Cunnings, I. (2017). Parsing and working memory in bilingual sentence processing. Bilingualism: Language and Cognition, 20, 659-678.

Deutsch, A., Frost, R., \& Forster, K. I. (1998). Verbs and nouns are organized and accessed differently in the mental lexicon: evidence from Hebrew. Journal of Experimental Psychology: Learning, Memory, and Cognition, 24, 12381255.

Farhy, Y., Veríssimo, J., \& Clahsen, H. (2017). Universal and particular in morphological processing: Evidence from Hebrew. The Quarterly Journal of Experimental Psychology. Advance online publication. doi:10.1080/17470218.2017.1310917

Feldman, L. B., Kostić, A., Basnight-Brown, D. M., Đurđević, D. F., \& Pastizzo, M. J. (2010). Morphological facilitation for regular and irregular verb formations in native and non-native speakers: Little evidence for two distinct mechanisms. Bilingualism: Language and Cognition, 13, 119-135.

Fraundorf, S. H., \& Jaeger, T. F. (2016). Readers generalize adaptations to newly-encountered dialectal structures to other unfamiliar structures. Journal of Memory and Language, 91, 28-58.

Freynik, S., Gor, K., \& O'Rourke, P. (2017). L2 processing of Arabic derivational morphology. The Mental Lexicon, 12, 21-50.

Frost, R., Kugler, T., Deutsch, A., \& Forster, K. I. (2005). Orthographic structure versus morphological structure: Principles of lexical organization in a given language. Journal of Experimental Psychology: Learning, Memory and Cognition, 31, 1293-1326.

Frost, R., Forster, K. I., \& Deutsch, A. (1997). What can we learn from the morphology of Hebrew? A masked- 
priming investigation of morphological representation. Journal of Experimental Psychology: Learning, Memory, and Cognition, 23, 829-856.

Gonnerman, L. M., Seidenberg, M. S., \& Andersen, E. S. (2007). Graded semantic and phonological similarity effects in priming: Evidence for a distributed connectionist approach to morphology. Journal of Experimental Psychology: General, 136, 323-345.

Hopp, H. (2016). The timing of lexical and syntactic processes in second language sentence comprehension. Applied Psycholinguistics, 37, 1253-1280.

Itai, A., \& Wintner, S. (2008). Language resources for Hebrew. Language Resources and Evaluation, 42, 75-98.

Jacob, G., Heyer, V., \& Veríssimo, J. (2017). Aiming at the same target: A masked priming study directly comparing derivation and inflection in the second language. International Journal of Bilingualism. Advance online publication. doi: 10.1177/1367006916688333

Jaeger, T. F. (2008). Categorical data analysis: Away from ANOVAs (transformation or not) and towards logit mixed models. Journal of Memory and Language, 59, 434-446.

Kirkici, B., \& Clahsen, H. (2013). Inflection and derivation in native and non-native language processing: Masked priming experiments on Turkish. Bilingualism: Language and Cognition, 16, 776-791.

Krause, H., Bosch, S., \& Clahsen, H. (2015). Morphosyntax in the bilingual mental lexicon. Studies in Second Language Acquisition, 37, 597-621.

Lo, S., \& Andrews, S. (2015). To transform or not to transform: Using generalized linear mixed models to analyse reaction time data. Frontiers in Psychology, 6:1171.

Marslen-Wilson, W. D. (2007). Processes in language comprehension. The Oxford Handbook of Psycholinguistics, 11, 495-524.

Marslen-Wilson, W., Tyler, L. K., Waksler, R., \& Older, L. (1994). Morphology and meaning in the English mental lexicon. Psychological Review, 101, 3-33.

McDonald, J. L. (2006). Beyond the critical period: Processingbased explanations for poor grammaticality judgment performance by late second language learners. Journal of Memory and Language, 55, 381-401.
Neubauer, K., \& Clahsen, H. (2009). Decomposition of inflected words in a second language: An experimental study of German participles. Studies in Second Language Acquisition, 31, 403-435.

Norman, T., Degani, T., \& Peleg, O. (2016). Transfer of L1 visual word recognition strategies during early stages of L2 learning: Evidence from Hebrew learners whose first language is either Semitic or Indo-European. Second Language Research, 32, 109-122.

Plaut, D. C., \& Gonnerman, L. M. (2000). Are nonsemantic morphological effects incompatible with a distributed connectionist approach to lexical processing? Language and Cognitive Processes, 15, 445-485.

Prévost, P., \& White, L. (2000). Missing surface inflection or impairment in second language acquisition? Evidence from tense and agreement. Second Language Research, 16, 103133

Say, T., \& Clahsen, H. (2002). Words, rules and stems in the Italian mental lexicon. In S. Nooteboom, F. Weerman, \& F. Wijnen (Eds.), Storage and computation in the language faculty (pp. 93-129). Dordrecht: Kluwer.

Silva, R., \& Clahsen, H. (2008). Morphologically complex words in L1 and L2 processing: Evidence from masked priming experiments in English. Bilingualism: Language and Cognition, 11, 245-260.

Veríssimo, J., \& Clahsen, H. (2009). Morphological priming by itself: A study of Portuguese conjugations. Cognition, 112, 187-194.

Veríssimo, J., Heyer, V., Jacob, G., \& Clahsen, H. (2017). Selective effects of age of acquisition on morphological priming: Evidence for a sensitive period. Language Acquisition. Advance online publication. doi:10.1080/10489223.2017.1346104

Voga, M., Anastassiadis-Symeonidis, A., \& Giraudo, H. (2014). Does morphology play a role in L2 processing? Two masked priming experiments with Greek speakers of ESL. Lingvistica Investigationes, 37, 338-352.

White, L. (2003). Second language acquisition and Universal Grammar. Cambridge: Cambridge University Press. 